\title{
PROGRAMA DE EXTENSAO UNIVERSITÁRIA MACKVIDA: PROMOVENDO DESENVOLVIMENTO E SAÚDE
}

\author{
Sheila Carla Souza ${ }^{1}$ \\ Roseli Fernandes Lins Caldas ${ }^{2}$ \\ Jan Carlo Morais O. Bertassoni Delorenzi ${ }^{3}$ \\ Persio Ribeiro Gomes Deus ${ }^{4}$
}

\begin{abstract}
RESUMO: Este texto apresenta a implantação, a evolução e a consolidação do programa de extensão MackVIDA, do Decanato de Extensão da Universidade Presbiteriana Mackenzie (UPM), que, atualmente, contempla tanto comunidade interna quanto externa da Universidade, com a proposta de promover ações de prevenção e valorização da vida, considerando a importância do desenvolvimento integral do ser humano. Assim, o objetivo do presente texto é divulgar as principais ações desenvolvidas pelo MackVIDA na última década e apresentar os doze projetos de extensão universitária que se consolidaram a partir de experiências, observações, registros e coleta de dados que agregaram um caráter empírico satisfatório, efetivando-se a consolidação dos projetos de extensão que funcionam regularmente nesta Instituição. Finaliza-se com a certeza dos benefícios oriundos da extensão universitária para a comunidade de uma forma geral, reiterandose que a Universidade necessita cumprir seu papel político e social alicerçada no tripé ensinopesquisa-extensão já proclamado pelas lideranças governamentais ligadas à área da educação.
\end{abstract}

PALAVRAS-CHAVE: Extensão universitária. Mackvida. Projetos de extensão.

\section{University extension program MackVIDA: development and health promotion}

\begin{abstract}
This paper presents the implementation, development and consolidation of the extension program called MackVIDA linked to the Vice-Rectory of Extension of the Mackenzie Presbyterian University (UPM). Focused both in internal and external community, the purpose of this program is to promote prevention and valuing life actions, considering the importance of the whole development of the human being. Therefore, this article aims to convey the main actions developed by MackVIDA during the last decade and to present its 12 extension projects that had been consolidated from experiences, observations, records and data collection that made the study satisfactorily empirical, and effectively consolidated these projects, which were regularly implemented in the university. It is believed that the general community does benefit from the university extension activities, reinforcing that the university must fulfill its political and social role, based on the tripod teaching-research-extension already proclaimed by government leaders linked to the education area.
\end{abstract}

\footnotetext{
${ }^{1}$ Doutoranda em Neurociências e Comportamento Humano pela Universidade de São Paulo, professora nos cursos de Pedagogia e Psicologia da Universidade Presbiteriana Mackenzie (sheila.souza@mackenzie.br).

2 Doutora em Psicologia Escolar e do Desenvolvimento Humano pela Universidade de São Paulo, professora no curso de Psicologia da Universidade Presbiteriana Mackenzie e coordenadora de programas de extensão (roseli.caldas@mackenzie.br; roselicaldas@uol.com.br).

${ }^{3}$ Doutor em Ciências (Biofísica) pelo Instituto de Biofísica Carlos Chagas Filho da Universidade Federal do Rio de Janeiro, chefe do Laboratório de Farmacologia e Toxicologia Aplicadas no Centro de Ciências Biológicas e da Saúde e professor nos cursos de Ciências Biológicas e Farmácia da Universidade Presbiteriana Mackenzie (jan.bertassoni@mackenzie.br).

${ }^{4}$ Mestre em Ciênçias das Religiões pela Universidade Presbiteriana Mackenzie, onde atua como professor, diretor técnico de saúde do Hospital Psiquiátrico da Água Funda (persio.deus@mackenzie.br).
} 
KEYWORDS: University extension. Mackvida. Extension projects.

\section{INTRODUÇÃO}

A chegada à Universidade é um momento almejado por jovens de todas as classes sociais, não apenas no Brasil, mas também de outros países do mundo. Este é um momento rico, pois é permeado de expectativas e, também, de muita ansiedade. Devido a diversas alterações nas políticas públicas de educação na última década, o ingresso desses jovens no ambiente universitário acontece cada vez mais cedo. A proximidade etária da adolescência, com todas as suas dúvidas e dilemas e as exigências da vida adulta, é elemento a ser considerado na dificuldade para tomar decisões, especialmente às relacionadas às suas atitudes e escolhas diante da vida em geral e da sua saúde em particular.

As bases teóricas sobre a adolescência, construídas ao longo do tempo pela Psicologia, têm sido rediscutidas a partir de novas perspectivas. Visões marcadas pelo senso comum apontam a adolescência como fase de rebeldia, agressividade ou isolamento. Assim, concepções a respeito do adolescente, em boa parte das políticas públicas, associam-no à violência, à drogadição, ao descontrole social e sexual, enfim, a uma série de elementos pouco favoráveis (CHECCIA, 2010).

É possível romper com tais pressupostos, considerando um referencial histórico-cultural no campo da Psicologia do Desenvolvimento e da Educação que permite buscar a conscientização sobre as potencialidades nos jovens e sua importante função na sociedade. Deste modo, a atenção à formação holística dos jovens universitários deve ser prioritária nas Instituições de Ensino Superior (IES), considerando a necessidade de integração entre a pessoa e sua formação acadêmico-profissional. Além disso, o desenvolvimento profissional não pode ser fundamentado, unicamente, em formação acadêmica e técnica de qualidade, mas em uma perspectiva que oportunize possibilidades de transformação na sociedade, ou seja, a preocupação na contribuição que esse indivíduo pode dar à sociedade e a valorização de suas atitudes/contribuições.

Sendo assim, as IES configuram-se como um espaço que possibilita aos discentes, compostos em sua maioria por adolescentes e jovens, conhecerem a si próprios, as necessidades do entorno e suas possibilidades de intervenção, enquanto agentes de transformação da realidade social. Entendese, assim, que a universidade pode ser um local, por excelência, para este desenvolvimento integral devido às diversas possibilidades de engajamento dos estudantes em atividades extensionistas, que, em última análise, podem ser entendidas como a aplicação ou a contribuição para a sociedade daquilo que foi produzido e aprendido no interior dos muros universitários.

Além disso, a Lei de Diretrizes e Bases da Educação Nacional - LDB 9394 (BRASIL, 1996) aponta que as Universidades brasileiras devem se organizar a partir do tripé Ensino, Pesquisa e Extensão, considerados eixos norteadores e indissociáveis das áreas educacionais. Especificamente, quanto ao eixo da Extensão, pode-se compreender como a contrapartida das instituições educacionais para a sociedade na qual estão inseridas.

Na Universidade Presbiteriana Mackenzie (UPM), a Extensão Universitária sempre foi 
considerada importante por sua Mantenedora, principalmente por se tratar de uma instituição com visão "[...] filantrópica e de perfil comunitário, que se dedica às ciências divinas e humanas; caracterizando-se pela busca contínua da excelência em ensino, pesquisa e extensão [...]" (INSTITUTO PRESBITERIANO MACKENZIE, 2012).

Em 2003, a Extensão foi institucionalizada por meio da criação da Coordenadoria de Extensão (COEX) e fortalecida, em 2004, com a transformação desta Coordenadoria em Decanato de Extensão (DEX). Atualmente, o DEX é um órgão de assessoria da Reitoria que responde por todas as atividades de extensão da UPM e que trabalha de forma articulada com o Decanato Acadêmico e com o Decanato de Pesquisa e Pós-Graduação.

Em 2003, foi criado o Programa MackVIDA, como iniciativa da Capelania Universitária, em parceria com os cursos de Psicologia e de Teologia. O objetivo estava voltado diretamente à prevenção às drogas. Em 2010, o Programa passou a ser vinculado ao DEX, ampliando suas perspectivas de ação, considerando a deliberação de recursos financeiros para sua organização extensionista e técnico-administrativa.

Atualmente, o Programa conta com um estagiário e uma equipe multidisciplinar, envolvendo quatro profissionais das áreas de Psicologia, Farmácia e Medicina, todos docentes da instituição, vinculados aos cursos de Pedagogia, Ciências Biológicas, Farmácia, Teologia e Psicologia. A equipe se reúne semanalmente para reuniões, debates sobre os projetos que estão em andamento, divisões de tarefas e idealização de novos projetos extensionistas que venham a atender às demandas da comunidade acadêmica da Instituição, bem como da comunidade externa, especialmente do entorno do Campus Higienópolis. Ainda, os recursos destinados ao MackVIDA possibilitaram a consolidação das ações que têm se ampliado a partir do estabelecimento de parcerias com os diversos cursos de graduação, ofertados em diferentes Centros Universitários e em diversas áreas do conhecimento.

Atualmente, o Programa MackVIDA visa atender, principalmente, duas frentes de ações: a) informar e possibilitar reflexão, especialmente aos alunos ingressantes, a respeito de tabaco, álcool e outras drogas; b) ampliar as oportunidades de convivência saudável e valorização de potencialidades. Em termos de público-alvo, está voltado para a comunidade interna (docentes, discentes, familiares e funcionários) e para a comunidade externa (população do entorno). Além disso, o Programa evoluiu, possibilitando aos Centros Universitários, por meio de seus diversos cursos e corpo docente, participarem mais efetivamente da extensão, contemplando ações conjuntas por meio do material produzido na UPM, traduzindo-se em benefícios à qualidade de vida dos que delas participam. Vida, compreendida no seu sentido amplo, integrando aspectos físicos, espirituais, sociais e psicológicos dos indivíduos.

Cabe aqui, breve reflexão sobre o que se entende por qualidade de vida e saúde. A definição pela Organização Mundial de Saúde (OMS) tem sido contestada por estudos que a apontam como uma visão positivista. Segundo Callahan (1973), para a OMS, saúde não é apenas ausência de doença, mas a situação de perfeito bem-estar físico, mental e social. Esta definição, embora avançada para a época, pode hoje ser questionada e tida como irreal e reducionista, à medida que a qualidade de vida é algo intrínseco, a ser conquistada pelo próprio indivíduo. 
Indubitavelmente, há indicadores de qualidade de vida e saúde que são fundamentais para a proposição de políticas públicas que garantam educação e saúde à população. Entretanto, é preciso ter cautela com a utopia da possibilidade de "perfeito bem-estar". É necessário, também, observar a concepção de continuidade entre o psíquico e o somático, considerando diversos fatores que podem afetar diretamente o que se compreende por "qualidade de vida".

Destaca-se que as injunções sociais atuam intensamente sobre este aparato complexo que é o sujeito. O estilo e o ritmo de vida impostos pela cultura, a modalidade da organização do trabalho, a vida nas metrópoles, entre outros fatores, poderiam fazer pensar, até mesmo em uma suposta unidade "sócio psicossomática" (FERRAZ; SEGRE, 1997).

Deste modo, a vida acadêmica, como uma das áreas fundamentais na vida dos jovens que a ela têm acesso, pode ser fator de preponderante influência nas demais instâncias de sua existência. Neste sentido, destaca-se o uso de drogas e suas consequências adversas, sobretudo aos estudantes universitários. Este é um tema relevante e de preocupação social, uma vez que estudos recentes têm confirmado o consumo mais intenso e frequente entre os universitários se comparados à população em geral (ANDRADE; DUARTE; OLIVEIRA, 2010).

O I Levantamento Nacional sobre o uso de álcool, tabaco e outras drogas, pesquisa realizada com 18 mil universitários das 27 capitais brasileiras, revelou que apenas 28\% das 114 IES participantes relataram ter desenvolvido alguma modalidade de programa ou projeto referente à prevenção e/ou orientação e/ou assistência de seus alunos voltados às temáticas de saúde e drogas. Tais dados expressam relevância de formação integral e indicam a necessidade do desenvolvimento de programas interventivos voltados à orientação dos jovens sobre os malefícios do uso de drogas. No entanto, é escasso o número de IES que contam com programas extensionistas que contemplem, na formação do universitário, a inclusão de temas referentes ao cuidado com a vida e a saúde (ANDRADE; DUARTE; OLIVEIRA, 2010).

Frente ao descortinamento dessas informações de relevância social, retomam-se os objetivos deste texto, que visa divulgar as principais ações desenvolvidas pelo MackVIDA na última década e apresentar os 12 projetos de extensão universitária que se consolidaram a partir de experiências e observações, agregando um caráter empírico satisfatório e efetivando a consolidação dos projetos de extensão que funcionam regularmente na UPM.

Finaliza-se esta introdução, reiterando-se que o Programa MackVIDA está fundamentado na concepção de promoção de saúde em detrimento do uso de drogas. Daí a realização de atividades voltadas à valorização da saúde e da vida, não se focando apenas na preocupação em mostrar que o uso de tabaco, álcool e outras drogas é nocivo ao indivíduo, mas que há um mundo, uma vida muito mais profícua e feliz, desvinculada das drogas. 


\section{METODOLOGIA}

A seguir, estão apresentadas as ações praticadas pelo MackVIDA, explicitando o tipo e objetivo de cada evento, bem como os participantes, o local e os procedimentos adotados para coleta e mensuração dos dados.

\section{Ciclo de palestras}

No início de cada semestre, são ministradas palestras sobre prevenção ao uso de tabaco, álcool e outras drogas por renomados especialistas internos e externos (convidados de outras Instituições) a todos os alunos ingressantes, contemplando mais de 2.000 calouros por ano. Os objetivos são discutir, refletir e apresentar informações sobre o uso de tabaco, álcool e outras drogas, enfatizando-se a valorização à vida. As palestras são ministradas nos campi da UPM localizados no Estado de São Paulo, a saber: Higienópolis, Alphaville e Campinas.

A pertinência, a temática e a apresentação das palestras são avaliadas pelos alunos participantes por meio de questionário multimodal tipo Likert. Tal questionário apresenta o objetivo das palestras e é composto por duas perguntas: 1) relevância do evento; e 2) pertinência do evento. Ambas as perguntas possuem escala de 0 a 10 , onde zero representa total insatisfação, e dez, total satisfação com o evento. O questionário possui espaço para sugestões e críticas, a fim de que o aluno possa acrescentar seu comentário por escrito. Por fim, os questionários não identificáveis são entregues no início de cada palestra e devolvidos de maneira espontânea pelos alunos ao término de cada evento.

\section{Sarau Universitário}

Realizado mensalmente, em parceria com o Centro de Comunicação e Letras (CCL) da UPM e Diretório Central dos Estudantes (DCE), tem como objetivo oferecer um espaço para que os alunos divulguem suas aptidões musicais e partilhem seus talentos artísticos. As inscrições são abertas a todo corpo discente e realizadas via internet.

Os participantes apresentam canções de variados gêneros musicais, realizam apresentações instrumentais, declamam poesias de autores da literatura brasileira ou de autoria própria, bem como participam por meio de outras expressões culturais como pintura e expressão corporal.

Os saraus ocorrem na Praça de Alimentação do Campus Higienópolis, uma vez a cada mês letivo, com duração de duas horas, e contam com uma média de dez apresentações para um público itinerante de, aproximadamente, 250 pessoas que ocupam este espaço de alimentação/convivência social.

A pertinência do evento também é avaliada pelo público ouvinte por meio de questionário multimodal tipo Likert, que segue o mesmo procedimento já explicitado na seção anterior. 


\section{Campanhas}

Com o objetivo de promover o engajamento dos acadêmicos em ações sociais, as campanhas têm como objetivo principal informar sobre saúde e sobre ações sociais. Assim, busca-se a sensibilização e a conscientização a partir de datas especiais (como, por exemplo, o Dia Mundial sem Tabaco), promovendo ações de cunho informativo e de orientação para alunos, professores e funcionários da UPM e comunidade externa, com campanhas voltadas à doação de sangue e cadastramento para doação de medula óssea. As ações sociais são desenvolvidas por meio de campanhas de doação de sangue, arrecadação de alimentos e agasalhos, visitas e apoio a instituições filantrópicas e ONGs, dentre outras.

A avaliação é feita pela equipe do programa, de maneira qualitativa, a cada término de ação, estabelecendo-se como critério o grau de impacto e o número de participantes em cada evento.

\section{Descarte de medicamentos}

Uma vez que medicamentos são produtos químicos, biológicos ou biotecnológicos especiais, desenvolvidos com a finalidade de diagnosticar, prevenir, curar doenças ou aliviar seus sintomas, sendo produzidos com rigoroso controle técnico para atender às especificações dos organismos nacionais e internacionais de fiscalização (ANVISA, 2010), é de suma importância dar-lhes destinação adequada quando não apresentam mais utilidade terapêutica.

Em atenção a essa questão, o Programa MackVIDA realizou, em 2011, levantamento quantitativo e qualitativo sobre a compreensão que a população do entorno do Campus Higienópolis tem sobre o descarte de medicamentos. No total, 400 pessoas foram entrevistadas.

O instrumento de avaliação utilizado foi questionário com registro do grau de conhecimento sobre o descarte de medicamento. Durante a abordagem, os entrevistados receberam material informativo sobre o tema.

\section{Filmes e Debates}

Apresentação de filmes que estimulem a reflexão em estudantes sobre temas polêmicos vivenciados pela sociedade contemporânea é uma das ações realizadas pelo UPM. Em parceria com o Centro de Arte e Cultura (CAC) da UPM, no Campus São Paulo, são exibidos dois filmes a cada semestre. A escolha do tema/filme é realizada pela equipe de professores do MackVIDA e do CAC. De maneira geral, para cada filme exibido, há participação de trinta alunos e quatro docentes de diferentes áreas de conhecimento.

A avaliação é feita pela equipe do programa, de maneira qualitativa, a cada término de ação, 
estabelecendo-se como critério o grau de impacto o número de participantes em cada evento.

\section{Recepção Solidária de alunos ingressantes}

Algumas campanhas e ações específicas aos alunos ingressantes, como movimentos sociais e palestras propostas pelo MackVIDA são vinculadas à "Recepção Solidária", importante atividade da universidade, realizada semestralmente no início de cada semestre, cujos, princípios de integração e solidariedade têm evidente consonância com a finalidade do programa.

A mobilização dos alunos veteranos na recepção aos calouros tem-se dado pelos mais diversos caminhos, como organização de Flash Mob, gincanas de integração, atividades esportivas, dentre outras.

A avaliação é feita pela equipe do programa, de maneira qualitativa, a cada término de ação, estabelecendo-se como critério o grau de impacto e o número de participantes.

\section{Rede Social}

Visando estabelecer mediação entre a academia e a comunidade do entorno do Campus Higienópolis, o programa MackVIDA participa ativamente de rede social do bairro, que congrega moradores e instituições, visando à melhoria da qualidade de vida dos moradores. Essa parceria tem se constituído em atividade extensionista por excelência, possibilitando o envolvimento de alunos e professores em atividades no local, por meio do desenvolvimento de ações socioculturais, campanhas, informações e apoio à comunidade.

A avaliação é feita pela equipe do programa, de maneira qualitativa, a cada término de ação, estabelecendo-se como critério o grau de impacto e o número de participantes.

\section{Projeto acolhimento de pais no vestibular}

Semestralmente, no Campus São Paulo, é realizado esse projeto durante a realização das provas seletivas para ingresso na UPM. A média de adesão/participação é de 500 pais/acompanhantes ao ano. O projeto envolve: palavras de boas-vindas pelos dirigentes da instituição; uma "sala de estar" com bufê para acomodação dos acompanhantes; Tenda da Acolhida, com atividades dos diversos cursos e distribuição de pequenos brindes; Ciclo de Palestras, ministradas por professores da UPM sobre a prática profissional; passeio histórico pelo Campus Higienópolis, momento em que os pais podem conhecer um pouco mais a respeito dos mais de 140 anos da instituição.

A avaliação é feita pela equipe do programa, de maneira qualitativa, a cada término de ação, estabelecendo-se como critério o grau de impacto e o número de participantes. Além disso, a pertinência do evento é avaliada pelo próprio público envolvido por meio de questionário multimodal tipo Likert, que segue o mesmo procedimento já explicitado em seções anteriores. 


\section{Projeto Inclusão}

Idealizado pela equipe MackVIDA, o projeto apresenta a preocupação central de tornar o espaço universitário acolhedor e envolvido com questões de inclusão escolar/social de pessoas com deficiência. Dentre os objetivos do projeto, destacam-se: a) sistematizar as pesquisas promovidas pela UPM sobre as questões de inclusão escolar; b) aproximar e fortalecer os diferentes grupos de trabalhos das Unidades Universitárias da UPM, a fim de viabilizar ações práticas no que tange à inclusão escolar de pessoas com deficiência; c) sensibilizar a comunidade acadêmica para a realidade da inclusão escolar, priorizando intervenções práticas para a adequada acomodação de pessoas que apresentem quaisquer tipos de necessidades educacionais especiais.

Este projeto está em andamento e foi dividido em três etapas, sendo que a primeira e a segunda, respectivamente, de coleta de informações e diálogos com grupos de trabalhos envolvidos na questão da inclusão escolar, já foram realizadas.

\section{Participação na gestão de políticas públicas sobre drogas}

A docente responsável pela coordenação do Programa MackVIDA atua como representante da universidade na Câmara Técnica de Políticas Públicas sobre Drogas, vinculada à Coordenadoria de Políticas sobre Drogas da Secretaria de Justiça e Cidadania do Estado de São Paulo (COED). Tal oportunidade tem sido de grande valia para a proposta de ações, eventos e iniciativas que promovam a prevenção ao uso de drogas.

\section{Newsletter}

O Newsletter é um veículo de publicação online com cunho de prevenção primária. Valendo-se de breves notícias vinculadas por meio de mídia Indoor, busca oferecer, à comunidade acadêmica, oportunidade de informação e reflexão sobre temas importantes da vida, da ética e da saúde.

Instrumento de avaliação qualitativa em andamento.

\section{Apoio a alunos}

Ações destinadas ao encaminhamento de alunos que procuram assistência, acolhimento e escuta. Tais alunos são orientados nas necessidades emergentes e, conforme necessidade, encaminhados para atendimento psicológico sistemático. 


\section{RESULTADOS}

\section{Ciclo de Palestras}

A ação beneficiou mais de 1500 alunos ingressantes durante o $1^{\circ}$ semestre de 2013 , tendo avaliação positiva tanto na pertinência como na realização do evento. A partir desta informação quantitativa e por meio das anotações dos alunos (variável qualitativa), a equipe avaliou a positividade da ação e caminha para o aperfeiçoamento do evento de acordo com a opinião dos participantes que sugeriram nomes de palestrantes e outras temáticas de interesse.

Além disso, os registros dos participantes acerca do desconhecimento dos malefícios causados pelo uso/abuso de tabaco/álcool/outras drogas suscitaram questionamentos sobre a conduta das palestras realizadas para este público, fato este que contribuiu para o aperfeiçoamento do evento. Apresenta-se, no ANEXO 1, um exemplo de avaliação do Ciclo de Palestras.

\section{Sarau Universitário}

Como exemplo, indicamos uma avaliação em que 98\% dos 188 respondentes do questionário de avaliação consideraram o evento pertinente e satisfatório. A partir desta informação quantitativa, a equipe avaliou a relevância e continuidade do Sarau Universitário. Ainda, por meio das anotações dos alunos (variável qualitativa), a equipe realizou algumas alterações nos formatos de apresentações, elencando maior variabilidade de apresentações, além da musical, e também realizou reunião com equipe técnica de apoio para melhoria/controle do áudio durante a realização do evento. Apresenta-se, no ANEXO 2, um exemplo de avaliação do Sarau Universitário.

\section{Campanhas}

De acordo com a avaliação feita pela equipe do programa, optou-se pela concentração de ações em campanhas de doação de sangue e campanhas voltadas às drogas lícitas, especialmente quanto ao uso de tabaco e abuso de álcool. Pretende-se ampliar as ações por meio da realização de parcerias e eventos externos à Universidade. Como exemplo, citamos a parceria com a Aliança de Controle do Tabagismo (ACT).

\section{Descarte de Medicamentos}

A partir da resposta de 400 entrevistados, confirmou-se a hipótese da equipe do MackVIDA acerca da falta de conhecimento da população, indiferente de classe social e nível de escolaridade, quanto ao descarte adequado de medicamentos vencidos. 


\section{Filmes e Debates}

A partir da baixa frequência de ouvintes nas exibições de filmes durante o $1^{\circ}$ semestre de 2013 , a equipe está avaliando a necessidade de alteração do público-alvo do projeto.

\section{Recepção Solidária}

De maneira qualitativa, a equipe considera a atividade importante, pois atinge os objetivos de integração e solidariedade do programa MackVIDA. No entanto, pretende-se desenvolver instrumentos de avaliação mais eficazes que possam indicar quais eventos são mais aceitos e resultam em um maior impacto de mobilização da população jovem.

\section{Rede Social}

A equipe considera a atividade importante, pois atinge os objetivos de integração com a comunidade do entorno da UPM. Pretende-se desenvolver instrumentos de avaliação mais eficazes que possam indicar quais eventos são mais aceitos e resultam em um maior benefício de acordo com as demandas da população local.

\section{Projeto Acolhimento de Pais no Vestibular}

A partir do contato direto com os pais (diálogo e acompanhamento nas atividades) e, ainda, com base no aumento gradativo e significativo de inscritos para o evento, bem como a avaliação que tem sido realizada formalmente pelos pais participantes, a equipe considera a atividade importante, pois atinge os objetivos de acolhimento aos pais dos vestibulandos da UPM.

\section{Projeto Inclusão}

A coleta dos dados acerca da inclusão escolar de pessoas com deficiência realizada no Campus Higienópolis está em andamento. Dentre outros dados, destaca-se a necessidade de melhorias de acessibilidade no entorno da UPM, com vistas a garantir o deslocamento seguro e autônomo de alunos com deficiência física.

\section{Participação na gestão de políticas públicas sobre drogas}

Elaboração de ofício, encaminhado à gestão da COED, posicionando-se contrariamente à liberação 
de bebidas alcoólicas nos jogos da Copa do Mundo de 2014.

\section{Newsletter}

Considerando que a implantação ainda se encontra em sua fase inicial, a avaliação será realizada no final do ano vigente.

\section{Apoio a alunos}

Identificada a necessidade, são feitos encaminhamentos para tratamentos de saúde psicológica, psiquiátrica, física e espiritual. Este núcleo de apoio conta com a parceria da Capelania da UPM e da Clínica Psicológica do curso de Psicologia da UPM.

\section{CONSIDERAÇÕES FINAIS}

A concepção que rege o Programa sustenta que, para além do posicionamento claramente contrário ao uso de drogas e da responsabilidade na transmissão de informações a esse respeito, a Universidade deve criar espaços de potencialização dos alunos, por meio de atividades socioculturais que fomentem nos jovens o cuidado com a própria vida e a preocupação com a vida do outro. Na percepção dos autores deste texto, aqui está explicitada a relevância deste trabalho.

Como entidade confessional, a UPM preza pela valorização da espiritualidade e a Capelania Universitária da instituição é parceira do MackVIDA em diversas ações, contribuindo, principalmente, com reflexões devocionais. Além disso, o programa conta, também, com o apoio e a participação das diferentes Unidades Universitárias e cursos universitários do Mackenzie que, por meio da interação entre professores, alunos e representantes de instâncias gerenciais/ deliberativas, auxiliam nas ações idealizadas pela equipe MackVIDA, fortalecendo as ações extensionistas da Universidade a cada dia.

Os eventos realizados pelo MackVIDA atendem às demandas sociais e instigam a reflexão sobre as angústias dos indivíduos expostos a um sistema no qual o ser humano tem valor basicamente por seu poder de produção ou de consumo. Na chamada "sociedade de mercado", vê-se o homem como uma mera engrenagem na cadeia produtiva, esvaziado de valor interior. Nas grandes metrópoles marcadas pela falta de tempo, a impessoalidade transforma as pessoas em solitárias anônimas, relacionando-se por meio do que Bauman (2004) denomina de "amor líquido".

O ingresso na universidade é marcado por muitas mudanças e o jovem defronta-se com um excesso de informações intelectuais e técnicas, ao mesmo tempo em que nem sempre apresenta um desenvolvimento adequado das emoções para intermediar o diálogo entre a lógica e os afetos. Possuem 
muito "conhecimento", mas, à primeira dificuldade afetiva, todo o edifício lógico entra em colapso.

Finaliza-se esta breve apresentação das ações do Programa MackVIDA, indicando que, por meio da observação, já é possível constatar índices maiores de engajamento dos estudantes nas atividades extensionistas da UPM a partir da elevação do número de participantes nas ações, evidências de apoio dos gestores, professores e funcionários, envolvimento dos Coordenadores de Extensão e maior visibilidade do programa na instituição. Em especial, as campanhas informativas têm surtido excelentes resultados, motivo pelo qual as solicitações de apoio da instituição têm se mostrado mais frequentes, buscando-se aprimoramento e aprofundamento nas ações propostas.

Quanto aos resultados voltados ao comprometimento da universidade com a população, as redes de relacionamento têm sido ampliadas, possibilitando ações cada vez mais afinadas com as demandas da comunidade ao redor do campus universitário. Atividades conjuntas têm viabilizado eventos culturais e acadêmicos dirigidos ao público externo, possibilitando que seja cumprido o objetivo extensionista, por excelência, de fazer chegar à comunidade as expertises construídas na universidade.

Em todos estes aspectos têm sido observados resultados positivos tanto na melhoria da qualidade das ações como no número de participantes e apoio institucional. O programa MackVIDA tem se mostrado imprescindível como espaço de apoio e informação.

Por fim, explicita-se a necessidade de ampliação da realização e divulgação acadêmica de ações extensionistas promovidas por Instituições de Ensino Superior, visando ao aprimoramento e à aproximação das demandas sociais à realidade acadêmica.

\section{REFERENCIAS}

ANDRADE A. G.; DUARTE, P.C. A.V.; OLIVEIRA, L. G. Levantamento nacional sobre o uso de álcool, tabaco e outras drogas entre universitários das 27 capitais brasileiras. Brasília, DF: Secretaria Nacional de Políticas sobre Drogas, 2010.

ANVISA - Agência Nacional de Vigilância Sanitária. O que devemos saber sobre medicamentos. In: Cartilha de Orientação. Brasília, DF, 2010.

BAUMAN, Z. Amor líquido: sobre a fragilidade dos laços humanos. Rio de Janeiro: J. Zahar, 2004.

BRASIL. Lei de diretrizes e bases da educação nacional. Lei 9.394, de 20 de dezembro de 1996. Estabelece as diretrizes e bases da educação nacional. Brasília, DF: MEC, 1996.

CALLAHAN, D. The WHO definition of "health". The Hastings Center Studies, New York, v. 1, n. 3, p. 77-87, 1973.

CHECCHIA, A. Adolescência e escolarização numa perspectiva crítica em psicologia escolar. Campinas, SP: Alínea, 2010. 
FERRAZ, F. C.; SEGRE, M. O conceito de saúde. Revista de Saúde Pública, São Paulo, v. 31, n. 5, p. 538-542, out. 1997.

INSTITUTO PRESBITERIANO MACKENZIE. Disponível em <http://www.mackenzie.br/ visao.html>. Acesso em: 5 fev. 2013.

Submetido em 7 de março de 2013.

Aprovado em 12 de junho de 2013. 


\section{ANEXO I}

\section{CICLO DE PALESTRAS $1^{\circ}$ SEMESTRE DE 2013 - CAMPUS HIGIENÓPOLIS}

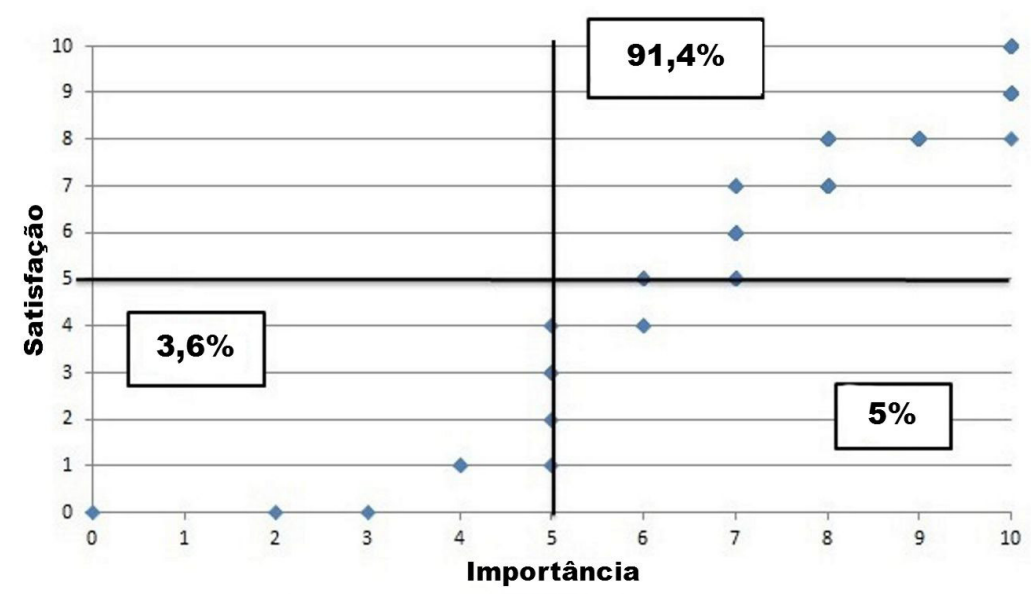

Total de Ingressantes Matutino = 1512

Público presente estimado $= \pm 600$

Questionários devolvidos $=\mathbf{2 8 0}$

\section{ANEXO 2}

SARAU MACKENZISTA - CAMPUS HIGIENÓPOLIS

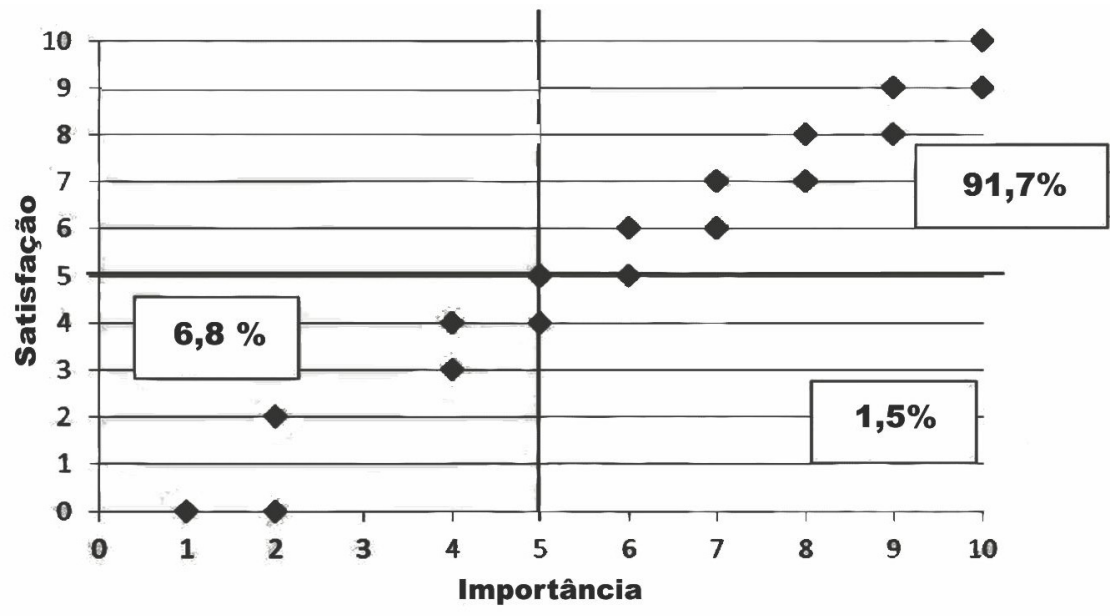

